\title{
Optimization of Solar Shading for a NZEB Kindergarten in Florence ${ }^{\dagger}$
}

\author{
Frida Bazzocchi *, Cecilia Ciacci and Vincenzo Di Naso \\ Department of Civil and Environmental Engineering, School of Engineering, University of Florence, \\ 50139 Florence, Italy \\ * Correspondence: frida.bazzocchi@unifi.it; Tel.: +39-0552758861 \\ + Presented at Innovations-Sustainability-Modernity-Openness Conference (ISMO'19), Bialystok, Poland, \\ 22-23 May 2019.
}

Published: 19 July 2019

\begin{abstract}
For the realization of a near-zero energy building (NZEB) school, it is important to define during the preliminary phase of the design process the type of solar shading to be used for each orientation (south, east, and west), as it strongly determines the appearance of the façade of the building. Given that this choice is also strictly linked to the energy balance of the building and to the thermal-hygrometric and visual wellbeing of occupants, it is necessary to combine both aspects. This study aims to analyze and optimize the solar shadings system of one of the new typological models for kindergarten in order to minimize the energy needs of the building. The proposed analysis in the paper is part of a broader work aimed at defining qualitative and quantitative guidelines for the design of NZEB kindergartens and elementary schools in the Mediterranean area.
\end{abstract}

Keywords: schools; NZEB; solar shading; energy savings

\section{Introduction}

The use of solar shadings in buildings affects energy balance and consequently energy consumption for heating, cooling, and lighting [1]. Furthermore, solar shadings influence both thermal-hygrometric wellbeing and visual comfort inside spaces [2]. The proper design of solar shadings can avoid overheating problems by regulating solar gains during the summer season inside rooms [3]. Nevertheless, concerning lighting, their use can lead to an increase in energy needs [4]. On the other hand, the choice of the type of solar shading strongly affects the appearance of the building. The main goal of this study is to evaluate the efficiency of the most common solar shadings for one of the new typological models for kindergarten in Italy [5]. This study aimed at minimizing the energy consumption for the analyzed building. This entails minimizing the sum of energy for the heating, cooling, lighting, and auxiliary systems and for the provision of hot water. The analysis was developed considering the building situated in the city of Florence, which is characterized by temperate climate (climate zone D) [6].

\section{Materials and Methods}

For the study of solar shading systems, the typological model for a kindergarten with a compact shape and internal courtyard was considered (Figure 1). It is characterized by a surface for the ground floor of about $900 \mathrm{~m}^{2}$ and a volume of about $5150 \mathrm{~m}^{3}$. It represents one of the three recurring reference models to realize energy efficient kindergartens in accordance to new educational and pedagogical methods [5]. In the model, a cross-laminated timber (XLAM) structure is used with wood fiber insulation for both the external envelope $\left(\mathrm{U}=0.20 \mathrm{~W} / \mathrm{m}^{2} \mathrm{~K}\right)$ and ventilated roof floor $\left(\mathrm{U}=0.12 \mathrm{~W} / \mathrm{m}^{2} \mathrm{~K}\right)$. For the ground 
floor layers, the solution with plastic formwork for underfloor ventilation with expanded polystyrene (EPS) insulation was used. Related to windows, an aluminum thermal break frame was adopted $\left(\mathrm{U}_{\mathrm{f}}=1.7 \mathrm{~W} / \mathrm{m}^{2} \mathrm{~K}\right)$ with a double glazing $\left(\mathrm{U}_{\mathrm{g}}=1.2 \mathrm{~W} / \mathrm{m}^{2} \mathrm{~K}\right.$, $\mathrm{TL}$ (Luminance Transmission $\left.)=74 \%, \mathrm{~g}=50 \%\right)$. The minimum value of the window-to-wall ratio (WWR) on every façade has been defined according to current health hygiene standards in Italy. For the southern façade, an overhang of $2 \mathrm{~m}$ is used to meet the shading required by regulations.

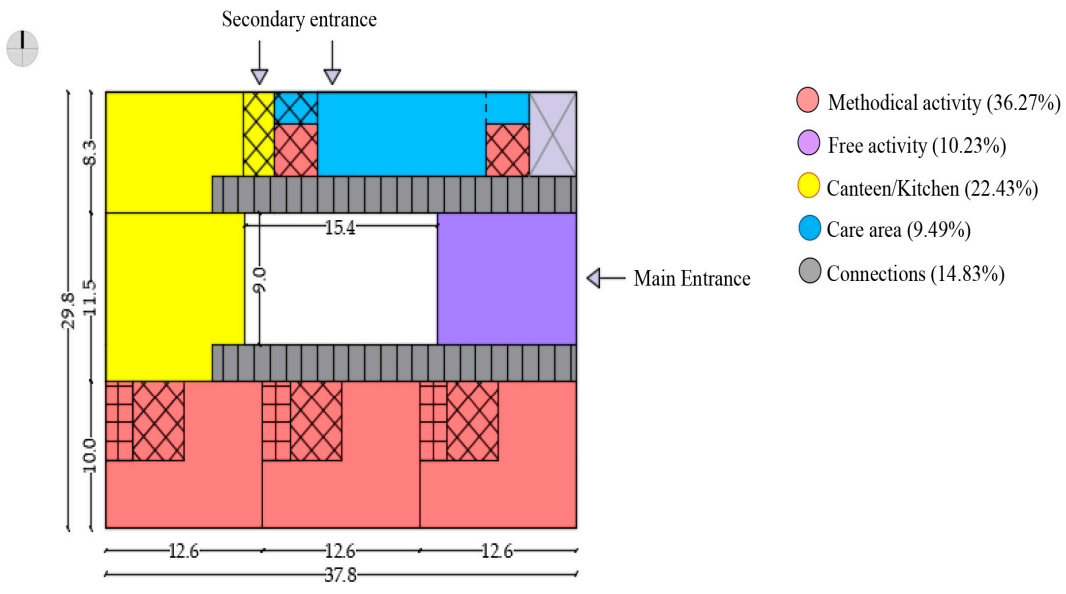

Figure 1. Typological model with compact shape and internal courtyard. The dimensions are listed in meters.

In order to evaluate the energy needs of the building, energy simulations in a dynamic condition were carried out through Energy Plus (NREL, Lakewood, CO, USA) software using Design Builder (Software Ltd., London, UK) as the graphical interface. Firstly, the analysis of the basic model, as briefly described above, developed a comparison between the most common solar shadings for the south orientation (blinds with high reflectivity slats with solar set point control, overhang, louvres, and a combination overhang/blinds). Then the possibility of adoption of external horizontal blinds, either fixed (always on) or automated with different types of control systems (schedule, solar, glare, inside air temperature, outside air temperature, cooling, night outside low air temperature, night inside low air temperature, and horizontal solar), are also analyzed (Table 1).

Table 1. Definition of different types of solar shading control systems.

\begin{tabular}{|c|c|}
\hline Type of Solar Shading Control System & Control Definition \\
\hline Always on & Shading devices are always activated \\
\hline Schedule & $\begin{array}{l}\text { Shading is on according to a schedule } \\
\text { (schedule equal to } 1 \text { is when shading occurs) }\end{array}$ \\
\hline Solar & Solar radiation $>120 \mathrm{~W} / \mathrm{m}^{2}$ \\
\hline Glare & Maximum glare index $>22$ \\
\hline Outside air temperature & Outside temperature $>24^{\circ} \mathrm{C}$ \\
\hline Inside air temperature & Inside temperature $>24^{\circ} \mathrm{C}$ \\
\hline Cooling & $\begin{array}{l}\text { Shading is on if zone cooling rate in the previous time } \\
\text { step is non-zero }\end{array}$ \\
\hline Night outside low air temperature & Air temperature $<0{ }^{\circ} \mathrm{C}$ \\
\hline Night inside low air temperature & Air temperature $<15^{\circ} \mathrm{C}$ \\
\hline Horizontal solar & Solar set point $>120 \mathrm{~W} / \mathrm{m}^{2}$ \\
\hline
\end{tabular}

Secondly, a parametric analysis was performed concerning the type of solar shading to be adopted on the southern façade with related control system with respect to one variation of WWR. In fact, to carry out a comparison between different solutions, this analysis was performed for both described basic model and refers to optimized one for the city of Florence with respect WWR 
according to previous study [7] (Florence optimum south WWR $=50 \%$ ). Finally, the influence on the building energy performance of vertical solar shadings with different coefficients of reflection (low $=0.2$; medium $=0.5$; high $=0.8$ ) of materials was evaluated for east and west orientations related to $\mathrm{WWR}$ variation (east $\mathrm{WWR}$ variation $=17 \%$; $29 \% ; 35 \%$, respectively; west $\mathrm{WWR}$ variation $=17 \%$; $23 \% ; 30 \%$, respectively).

\section{Results}

The performed simulations on the basic model point out that the variation of the typology of solar shading for the south orientation marginally affects $(\sim 1 \%)$ the final energy consumption for heating, cooling, and lighting (Table 2) with respect to the reference solution realized with a fixed overhang of $2 \mathrm{~m}$.

Table 2. Comparison of different types of solar shadings in terms of energy consumption (kWh/mª).

\begin{tabular}{|c|c|c|c|c|}
\hline Type of Solar Shading & $\begin{array}{l}\text { Heating } \\
\left(\mathrm{kWh} / \mathrm{m}^{2} \mathrm{a}\right)\end{array}$ & $\begin{array}{l}\text { Cooling } \\
\left(\mathrm{kWh} / \mathrm{m}^{2} \mathrm{a}\right)\end{array}$ & $\begin{array}{l}\text { Lighting } \\
\left(\mathrm{kWh} / \mathrm{m}^{2} \mathrm{a}\right)\end{array}$ & $\begin{array}{l}\text { Variation } \\
(\%)\end{array}$ \\
\hline $\begin{array}{l}\text { Internal blinds with high reflectivity slats } \\
\text { with solar set point control }\left(120 \mathrm{~W} / \mathrm{m}^{2}\right)\end{array}$ & 39.56 & 7.34 & 2.36 & $<1 \%$ \\
\hline $\begin{array}{l}\text { Overhang of } 2 \mathrm{~m}+\text { internal blinds with } \\
\text { solar set point control }\left(120 \mathrm{~W} / \mathrm{m}^{2}\right)\end{array}$ & 40.10 & 7.18 & 2.45 & $<1 \%$ \\
\hline $\begin{array}{l}\text { External horizontal louvres } \\
\text { (eight louvres) }\end{array}$ & 39.96 & 7.25 & 2.15 & $<1 \%$ \\
\hline $\begin{array}{l}\text { External blinds with solar set point } \\
\text { control }\left(120 \mathrm{~W} / \mathrm{m}^{2}\right)\end{array}$ & 40.44 & 7.23 & 2.43 & $1.40 \%$ \\
\hline
\end{tabular}

Figure 2 shows the variation in building consumption with respect to different solar shading control systems considering horizontal external blinds for the south orientation. The graph (Figure 2) points out that the automated movable solar shading leads to a decrease in the energy demand of the building with every examined control system with respect to fixed solar shading (always on). The solution that leads to a greater reduction in energy requirement, equal to $5 \%$ with respect to the fixed solar shading, is that with the outside air temperature control system (external temperature $>24^{\circ} \mathrm{C}$ ).

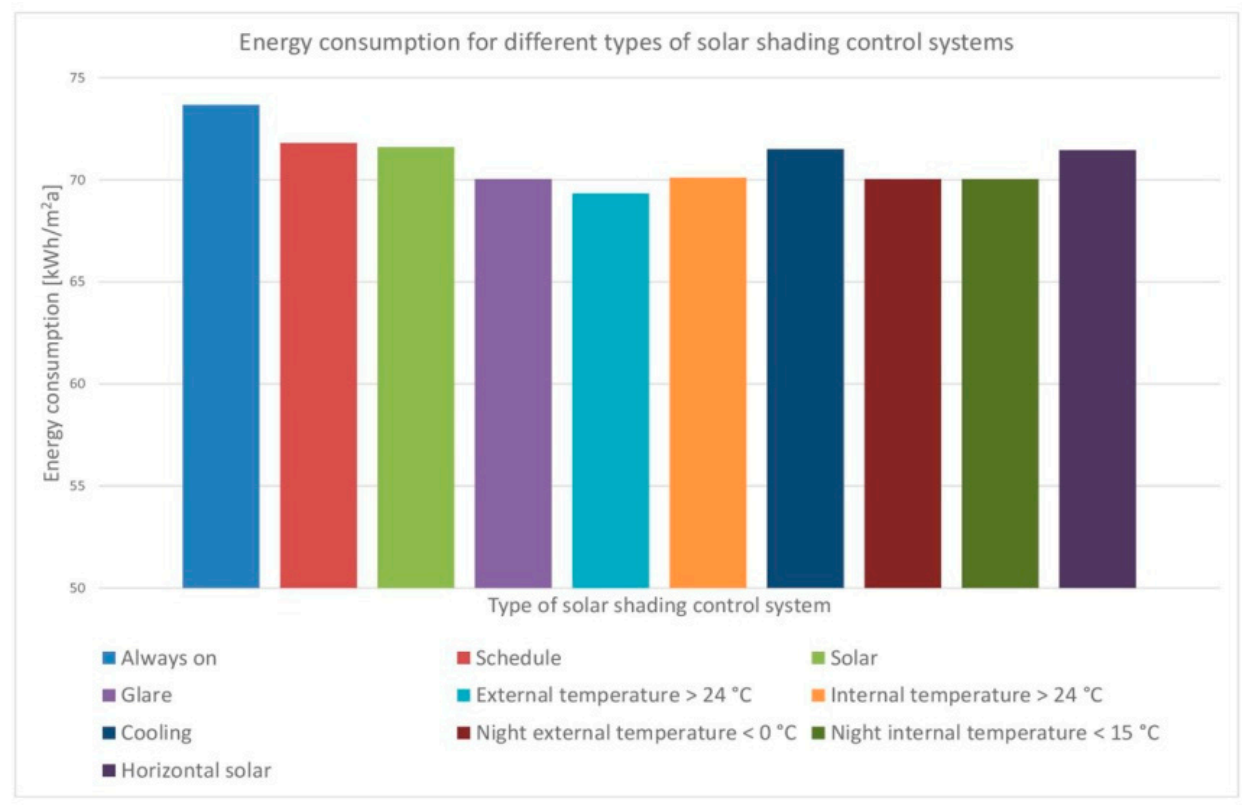

Figure 2. Energy consumption $\left(\mathrm{kWh} / \mathrm{m}^{2} \mathrm{a}\right)$ for different type of solar shading control systems. 
Regarding the study of the optimized model with respect to WWR, and therefore considering a WWR for the south orientation equal to $50 \%$, the trend of the energy consumption of the building with respect to the different type of control system applied to automated horizontal blinds for the south orientation is the same as in the previous case. However, in this case, compared to the same solar shading considered but fixed (always on) instead of automated, the decrease is equal to $6 \%$. Finally, the simulations concerning the use of east and west vertical solar protection for the examined building highlight that their use does not lead to significant advantages in terms of energy consumption $(<1 \%)$ for heating, cooling, and lighting. This situation also occurs with the increase in WWR for both east and west orientations.

\section{Discussion}

With regard to the simulations performed and the results achieved, it is essential to stress that the high ventilation air change rates required by current Italian regulation UNI (Italian National Agency of Unification) 10339 (June 1995-Appendix A) [8] inevitably and strongly affect the energy needs of the school by reducing the influence of other features, such as, for instance, the effect on energy balance of the different types of solar shading or the use of vertical solar protection for east and west orientations. For a building with this orientation and this distribution of spatial units and functional bands (Figure 1), the adoption of solar shadings for the south orientation is, however, necessary, as it allows an appropriate thermal-hygrometric and visual comfort in classrooms that are the spatial units with the higher occupancy during school time. Moreover, with respect to the definition of NZEB buildings [9], the use of solar shadings for the south orientation allows proper values to be obtained for the summer solar radiation surface [9]. Regarding east and west orientations, the use of vertical solar shadings does not significantly affect the energy needs because there are not windows for classrooms along these orientations.

\section{Conclusions}

In conclusion, the choice of the type of solar shading for the south orientation is independent from energy consumption of the building, as it has minimal influence $(<1 \%)$ for a building with this internal distribution. The use of an automated solar protection with a control system allows for the better energy performance of the school building in comparison to a fixed form of solar protection. Indeed, the automated horizontal blinds (with the control system based on external temperature $>24^{\circ} \mathrm{C}$ ) allows savings to be obtained in terms of energy compared to the fixed solar shading realized with an

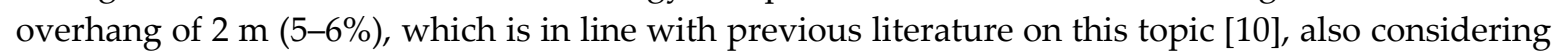
an increase in WWR. Instead, with regard to east and west façades, with respect to the typology of the analyzed building (Figure 1), the utilization of vertical solar shading does not entail any benefits, even in relation to the increase in the WWR. Finally, considering a different coefficient of reflection of vertical blinds for east and west façades, there are no substantial changes in energy needs of the building, even if the analysis points out that for the west orientation the medium coefficient of reflection is slightly better when also considering the increase in WWR, while for the east orientation the lower coefficient of reflection is slightly better.

Author Contributions: This paper was produced as a collaboration between the authors. F.B., C.C. and V.D.N. wrote the paper. C.C. did simulations with Design Builder.

Conflicts of Interest: The authors declare no conflict of interest.

\section{References}

1. Bellia, L.; Marino, C.; Minichiello, F.; Pedace, A. An overview on solar shading systems for buildings. Energy Procedia 2014, 62, 309-317, doi:10.1016/j.egypro.2014.12.392.

2. Karlsen, L.; Heiselberg, P.; Bryn, I.; Johra, H. Solar shading control strategy for office buildings in cold climate. Energy Build. 2016, 118, 316-328, doi:10.1016/j.enbuild.2016.03.014. 
3. Hashemi, A.; Khatami, N. Effects of Solar Shading on Thermal Comfort in Low-income Tropical Housing. Energy Procedia 2017, 111, 235-244, doi:10.1016/j.egypro.2017.03.025.

4. David, M.; Donn, M.; Garde, F.; Lenoir, A. Assessment of the thermal and visual efficiency of solar shades. Build. Environ. 2011, 46, 1489-1496, doi:10.1016/j.buildenv.2011.01.022.

5. Ciacci, C. Progettazione di scuole NZEB: Nuovi modelli tipologici per la scuola dell'infanzia e la scuola primaria in Italia. In Proceedings of the Colloquiate 2018: Edilizia Circolare tra Recupero/Riqualificazione e Rinnovo/Rigenerazione Urbana e Architettonica, Cagliari, Italy, 12-14 September 2018.

6. D.P.R. 26 August 1993, n.412. Regolamento recante norme per la progettazione, l'installazione, l'esercizio e la manutenzione degli impianti termici degli edifici ai fini del contenimento dei consumi di energia.

7. Ciacci, C.; Bazzocchi, F.; Di Naso, V.; Rocchetti, A. Influence of Window-Wall ratio on global energy consumption of Nzeb kindergartens in Italy. Build. Simul. 2019, 2019, in press.

8. UNI 10339, 2005. Impianti aeraulici a fini di benessere Generalità, classificazione e requisiti Regole per la richiesta d'offerta, l'offerta, l'ordine e la fornitura.

9. DM 26 June 2015. Applicazione delle metodologie di calcolo delle prestazioni energetiche e definizione delle prescrizioni e dei requisiti minimi degli edifici.

10. Winther, F.V.; Liu, M.; Heiselberg, P.; Jensen, R.L. Experimental and Numerical Analysis of Modelling of Solar Shading. Energy Procedia. 2017, 132, 472-477, doi:10.1016/j.egypro.2017.10.001

(C) 2019 by the authors. Licensee MDPI, Basel, Switzerland. This article is an open access article distributed under the terms and conditions of the Creative Commons Attribution (CC BY) license (http://creativecommons.org/licenses/by/4.0/). 